\title{
Broad-Spectrum Tunable Photoluminescent Material Based on Cascade Fluorescence Resonance Energy Transfer between Three Fluorophores

\author{
Encapsulated within the Self-assembled Surfactant Systems
}

\section{SUPPORTING INFORMATION}

Mohd Sajid Lone, ${ }^{a}$ Saima Afzal, ${ }^{a}$ Oyais Ahmad Chat, ${ }^{a, b}$ Parvaiz Ahmad Bhat, ${ }^{b}$ Rupam Dutta, ${ }^{c}$ Yongliang Zhang, ${ }^{d}$ Niloy Kundu, ${ }^{c, e}$ and Aijaz Ahmad Dara,*

a Physical Chemistry Division, Department of Chemistry, University of Kashmir, Hazratbal, Srinagar-190006, J\&K, India, 190006.

${ }^{b}$ Department of Chemistry, Govt. Degree College Pulwama-192301, J\&K, India

'Department of Chemistry, Indian Institute of Technology Kharagpur, Kharagpur-721302,

WestBengal, India

${ }^{d}$ Department of Chemical Engineering and Materials Science, University of Minnesota Twin Cities, 421 Washington Avenue, Minneapolis, 55455

e Environment Research group, Research and development, Tata steel, Jamshedpur-831001, Jharkhand, India

*Corresponding Author

A.A. Dar, Fax: + 91- 1942414049; Tel: + 91- 9906417902.

Email:aijaz n5@yahoo.co.in, aijazdar@kashmiruniversity.ac.in 
Writing tests: Writing tests were performed by employing the aqueous solutions of three fluorophores as fluorescent inks, with and without the micelles. The aqueous solutions of such fluorophores were used for the writing on ordinary filter paper. Due to the high fluidity of aqueous solutions of such fluorophores writing on the fluorophores were a bit difficult to carry out due to spreading problems of the liquid on the filter paper. In order to avoid that we have first drawn the letters on the filter paper by using the alginate non-fluorescent gels. After that the aqueous solutions of the fluorophores were used to write the letters by following the path as carved out by the gel.

Table S1: Table for Chemical Shifts of Various Protons of the Two Surfactants SDS and bmimDS in Absence and in Presence of Solubilizates

\begin{tabular}{|c|c|c|c|c|c|c|c|c|c|c|c|c|c|}
\hline System & & $\mathbf{a}$ & $\mathbf{b}$ & c & d & $\mathbf{e}$ & f & g & $\mathbf{h}$ & i & $\mathbf{j}$ & $\mathbf{k}$ & 1 \\
\hline bmimDS & $\begin{array}{l}\text { Pure } \\
\text { Pyrene } \\
\text { Cou480 } \\
\text { R6G }\end{array}$ & $\begin{array}{l}0.73 \\
0.71 \\
0.74 \\
0.72\end{array}$ & $\begin{array}{l}1.15 \\
1.12 \\
1.13 \\
1.14\end{array}$ & $\begin{array}{l}1.51 \\
1.50 \\
1.48 \\
1.50\end{array}$ & $\begin{array}{l}3.87 \\
3.87 \\
3.86 \\
3.86\end{array}$ & $\begin{array}{l}8.68 \\
8.67 \\
8.68 \\
8.65\end{array}$ & $\begin{array}{l}7.41 \\
7.40 \\
7.41 \\
7.37\end{array}$ & $\begin{array}{l}7.38 \\
7.37 \\
7.38 \\
7.33\end{array}$ & $\begin{array}{l}4.11 \\
4.10 \\
4.11 \\
4.08\end{array}$ & $\begin{array}{l}3.80 \\
3.80 \\
3.80 \\
3.77\end{array}$ & $\begin{array}{l}1.74 \\
1.73 \\
1.72 \\
1.73\end{array}$ & $\begin{array}{l}0.84 \\
0.83 \\
0.84 \\
0.83\end{array}$ & $\begin{array}{l}0.81 \\
0.79 \\
0.80 \\
0.79\end{array}$ \\
\hline SDS & $\begin{array}{l}\text { Pure } \\
\text { Pyrene } \\
\text { Cou480 } \\
\text { R6G }\end{array}$ & $\begin{array}{l}0.78 \\
0.74 \\
0.76 \\
0.77\end{array}$ & $\begin{array}{l}1.19 \\
1.16 \\
1.17 \\
1.19\end{array}$ & $\begin{array}{l}1.57 \\
1.56 \\
1.53 \\
1.53\end{array}$ & $\begin{array}{l}3.92 \\
3.91 \\
3.90 \\
3.88\end{array}$ & & & & & & & & \\
\hline
\end{tabular}




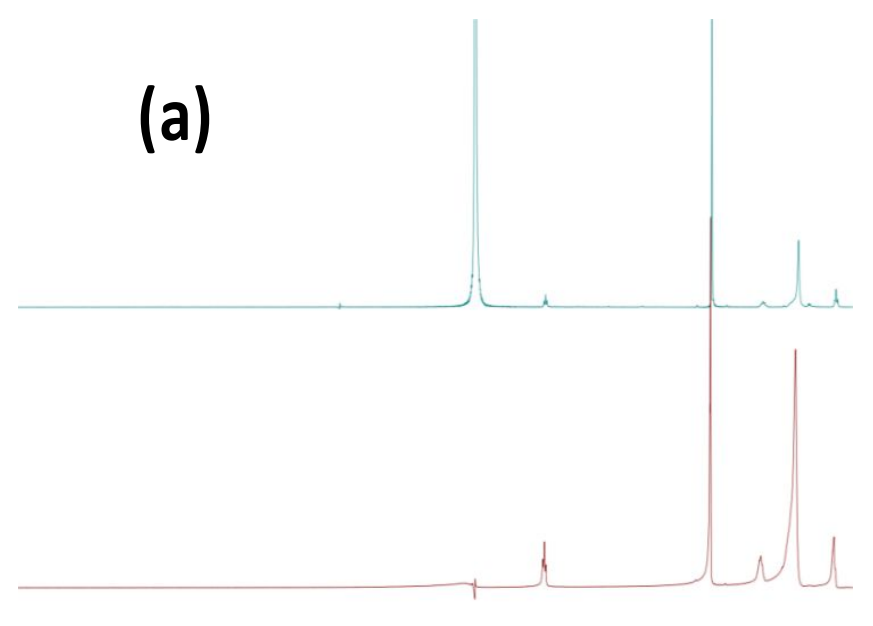

$\begin{array}{llllllllllllllllll}9.5 & 9.0 & 8.5 & 8.0 & 7.5 & 7.0 & 6.5 & 6.0 & 5.5 & 5.0 & 4.5 & 4.0 & 3.5 & 3.0 & 2.5 & 2.0 & 1.5 & 1.0\end{array}$
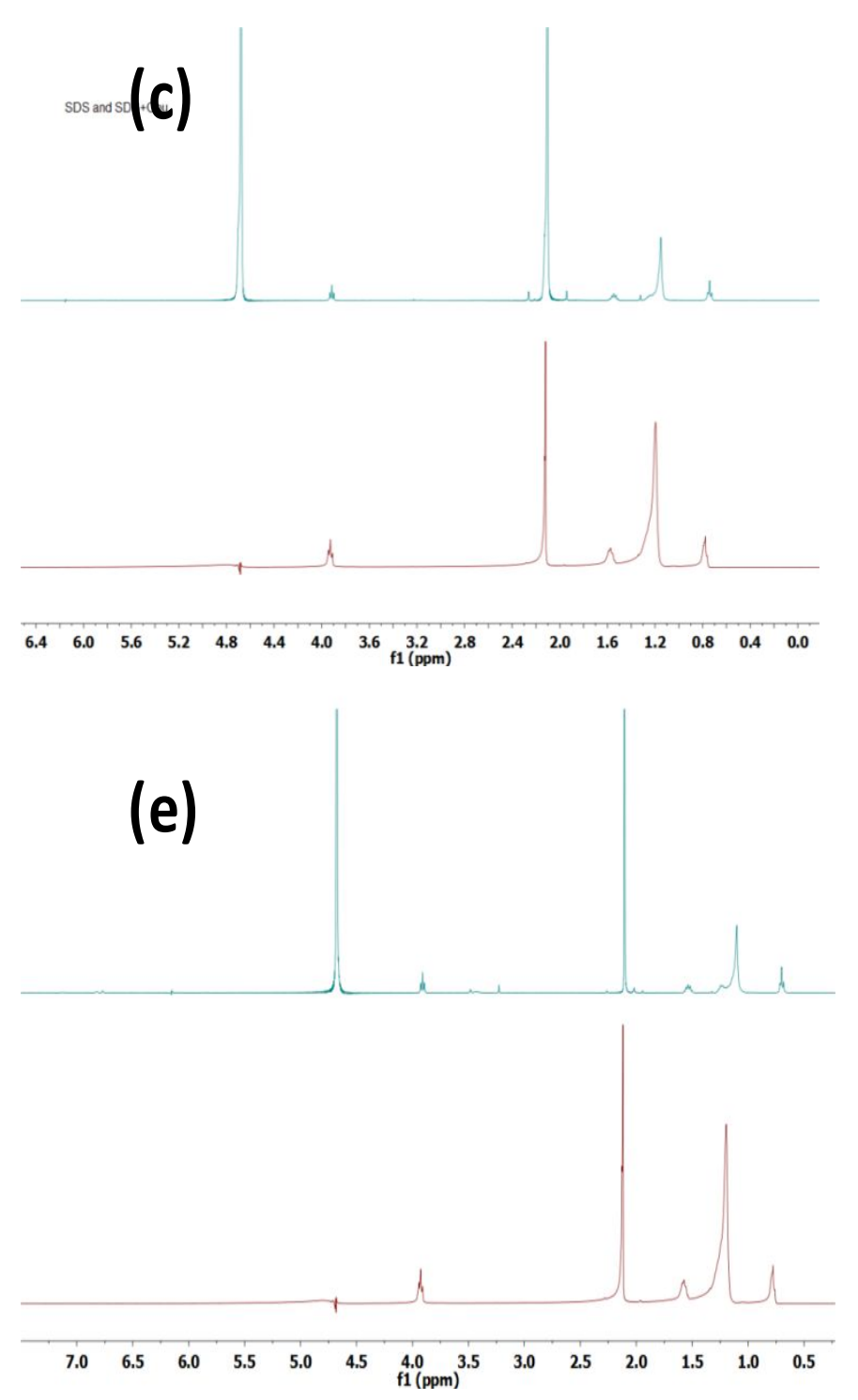
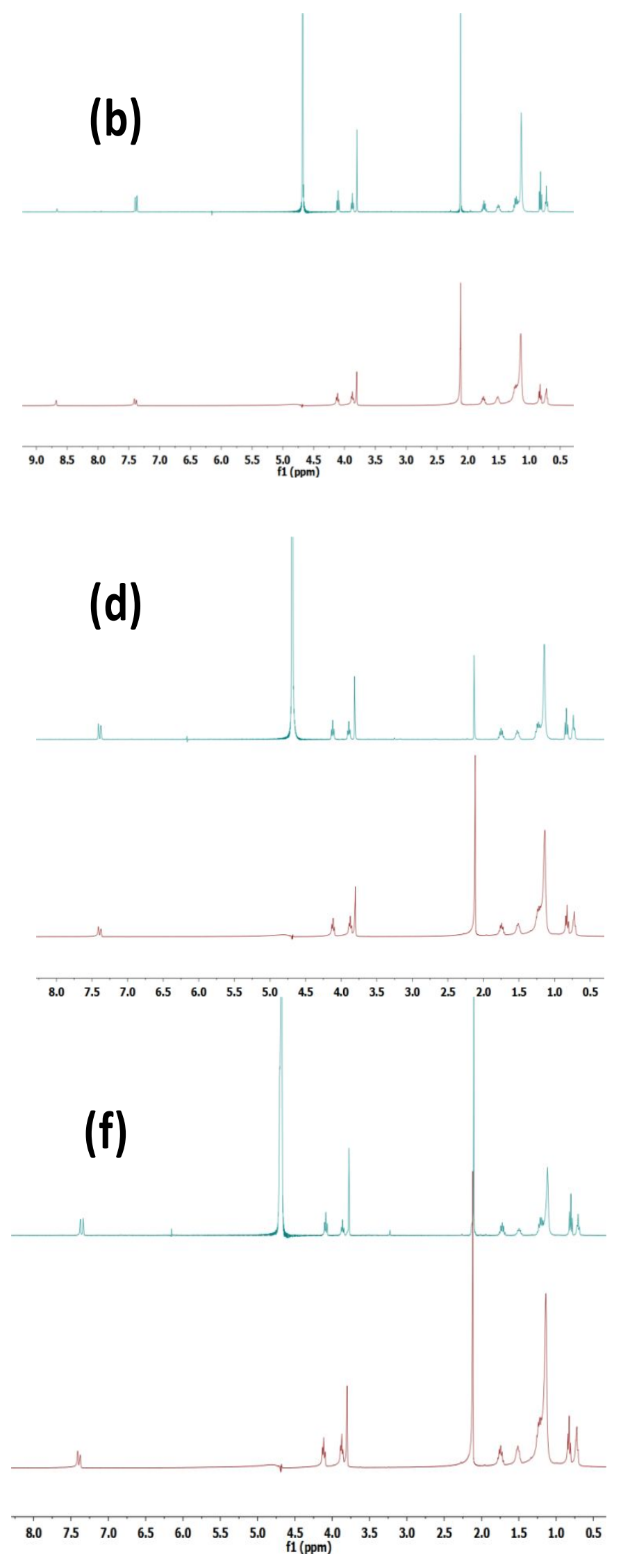
Fig. S1: (a) ${ }^{1} \mathrm{H}-\mathrm{NMR}$ spectra of SDS and SDS+ pyrene, (b) bmimDS and bmimDS + pyrene. (c) ${ }^{1} \mathrm{H}-\mathrm{NMR}$ spectra of SDS and SDS+Cou480 (d) bmimDS and bmimDS+Cou480. (e) ${ }^{1} \mathrm{H}-\mathrm{NMR}$ spectra of SDS and SDS+R6G (f) bmimDS and bmimDS+R6G.

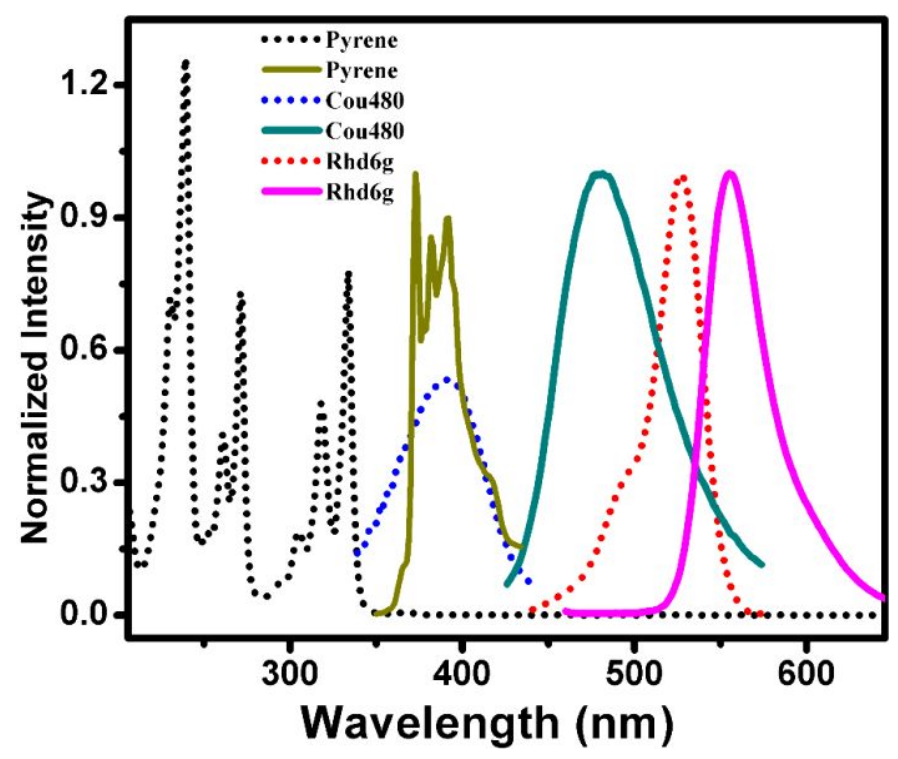

Fig. S2: Overlap spectra of the three fluorophores (emission= solid lines, absorption= dotted lines).

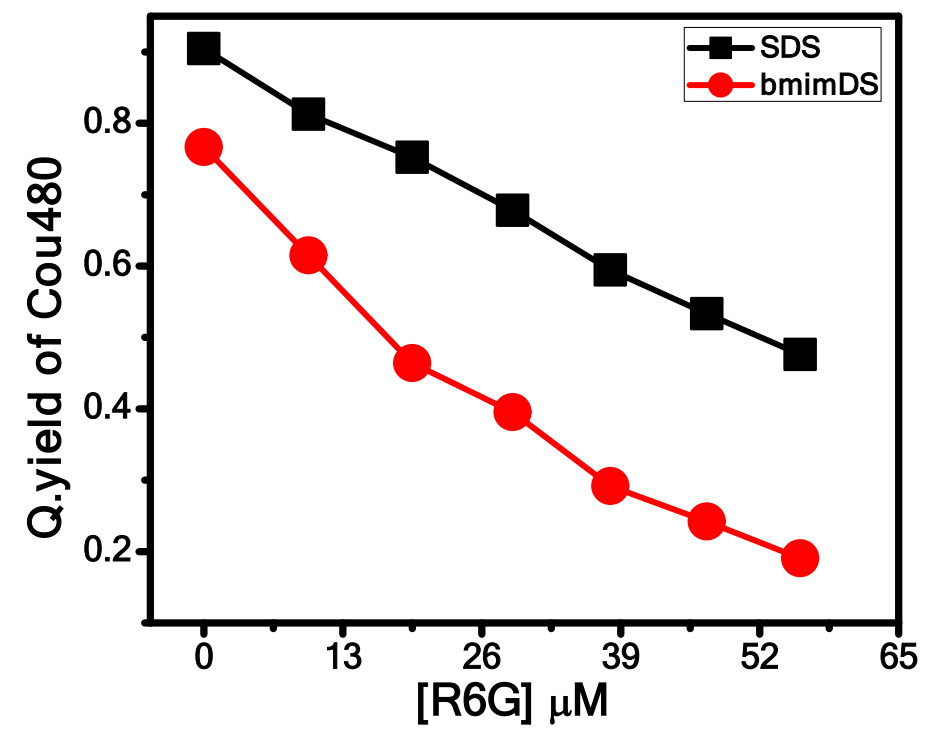


Fig. S3: Variation of quantum yield of Coumarin 480 in SDS and bmimDS with increasing the concentration of R6G.

Table S2: Decay Parameters of R6G at $336 \mathrm{~nm}$ and $402 \mathrm{~nm}$ in SDS and bmimDS

\begin{tabular}{|c|c|c|c|c|c|}
\hline System & $\tau_{1}(\mathbf{n s})$ & $\tau_{2}(\mathbf{n s})$ & $\mathbf{B}_{1}$ & $\mathbf{B}_{\mathbf{2}}$ & $\tau_{\text {avg }} \mathrm{a}(\mathrm{ns})$ \\
\hline \multicolumn{6}{|l|}{ SDS } \\
\hline R6G & 4.36 & 0 & 1.00 & 0 & 4.36 \\
\hline $\mathrm{R} 6 \mathrm{G}+\mathrm{Cou} 480$ & 4.52 & 0 & 1.00 & 0 & 4.52 \\
\hline R6G+Pyrene & 4.48 & 0 & 1.00 & 0 & 4.48 \\
\hline R6G + Pyrene + Cou 480 & 4.48 & 15.7 & 0.95 & 0.05 & 5.06 \\
\hline \multicolumn{6}{|l|}{ At $336 \mathrm{~nm}$} \\
\hline \multicolumn{6}{|l|}{ bmimDS } \\
\hline R6G & 4.37 & 0 & 1.00 & 0 & 4.37 \\
\hline $\mathrm{R} 6 \mathrm{G}+\mathrm{Cou} 480$ & 4.50 & 0 & 1.00 & 0 & 4.50 \\
\hline R6G+Pyrene & 4.20 & 0 & 1.00 & 0 & 4.20 \\
\hline R6G+Pyrene + Cou 480 & 4.78 & 16.1 & 0.93 & 0.07 & 5.47 \\
\hline \multicolumn{6}{|l|}{ SDS } \\
\hline R6G & 4.48 & 0 & 1.00 & 0 & 4.48 \\
\hline $\mathrm{R} 6 \mathrm{G}+\mathrm{Cou} 480$ & 4.36 & 6.08 & 0.39 & 0.60 & 5.40 \\
\hline \multicolumn{6}{|l|}{ At $402 \mathrm{~nm}$} \\
\hline \multicolumn{6}{|l|}{ bmimDS } \\
\hline R6G & 4.54 & 0 & 1.00 & 0 & 4.54 \\
\hline $\mathrm{R} 6 \mathrm{G}+\mathrm{Cou} 480$ & 12.7 & 5.05 & -0.24 & 1.24 & 6.25 \\
\hline
\end{tabular}
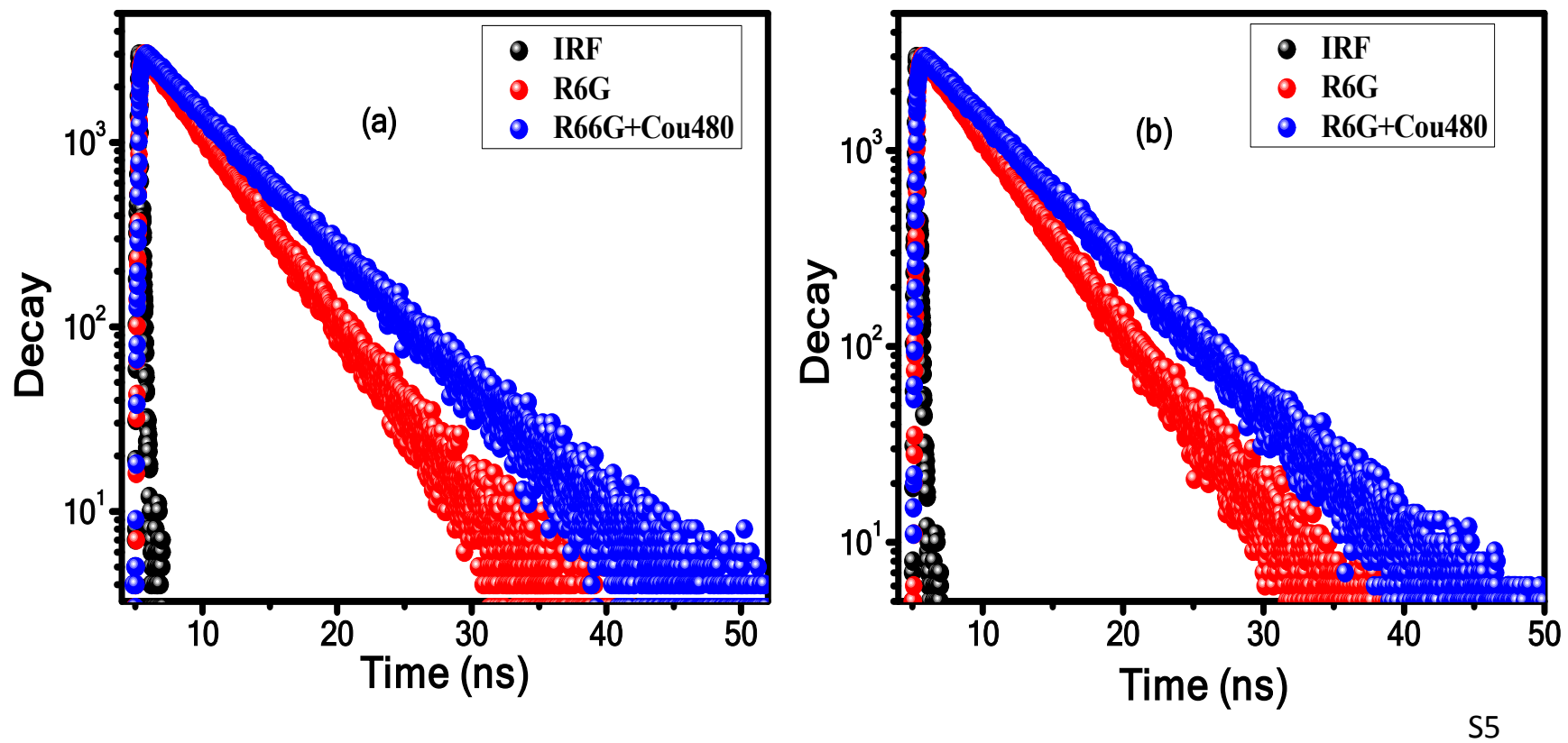
Fig. S4: Decay profile of R6G $(20 \mu \mathrm{M})$ with and without Cou480 (7 $\mu \mathrm{M})$ in (a) SDS (b) bmimDS (excitation laser $=402 \mathrm{~nm})$.

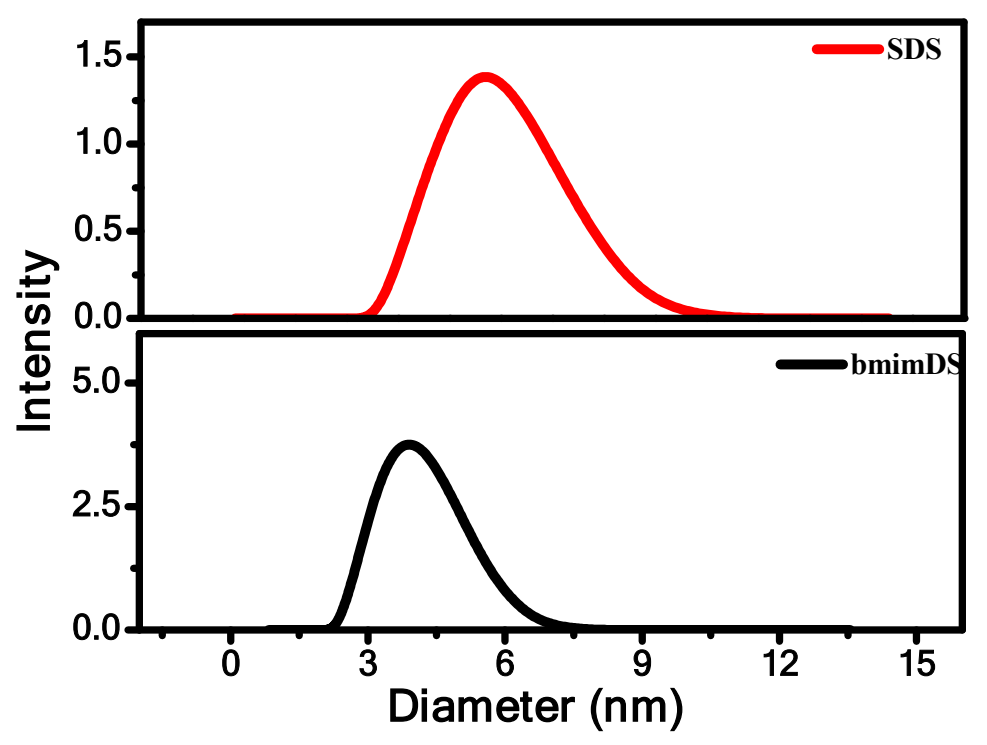

Figure S5: DLS of SDS and bmimDS micellar systems. 
Table S3: Parameters Showing the Intermolecular Distance Efficiency of the Two FRET Systems in SDS and bmimDS

\begin{tabular}{|c|c|c|c|c|c|c|}
\hline System & {$[\mathrm{Cou} 480] \mu \mathrm{M}$} & $\begin{array}{l}\text { Distance between } \\
\text { Pyrene and } \\
\text { Cou } 480\left(\mathrm{~A}^{0}\right)\end{array}$ & $\begin{array}{l}\text { Efficiency of } \\
\text { Pyrene and } \\
\text { Cou480 at } \\
334 \mathrm{~nm}\end{array}$ & {$[\mathrm{R6G}] \mu \mathrm{M}$} & $\begin{array}{l}\text { Distance } \\
\text { between } \\
\text { Cou480 } \\
\text { and } \\
\operatorname{R6G}\left(A^{0}\right)^{a}\end{array}$ & $\begin{array}{l}\text { Efficien } \\
\text { cy of } \\
\text { Cou } 480 \\
\text { and } \\
\text { R6G at } \\
402 \mathrm{~nm}^{\mathrm{a}}\end{array}$ \\
\hline bmimDS & $\begin{array}{c}5.95 \\
11.82 \\
17.60 \\
23.30 \\
28.91\end{array}$ & $\begin{array}{l}50 \\
47 \\
43 \\
37 \\
34\end{array}$ & $\begin{array}{l}44.1 \\
48.5 \\
46.8 \\
66.6 \\
71.9\end{array}$ & $\begin{array}{c}9.8 \\
19.51 \\
28.91 \\
38.05 \\
47.05 \\
55.81\end{array}$ & $\begin{array}{l}67 \\
62 \\
58 \\
52 \\
47 \\
44\end{array}$ & $\begin{array}{l}32.8 \\
37.3 \\
43.4 \\
51.5 \\
59.5 \\
66.0\end{array}$ \\
\hline SDS & $\begin{array}{c}5.95 \\
11.82 \\
17.60 \\
23.30 \\
28.91\end{array}$ & $\begin{array}{l}58 \\
54 \\
51 \\
47 \\
45\end{array}$ & $\begin{array}{l}26.2 \\
21.8 \\
36.6 \\
33.4 \\
51.9\end{array}$ & $\begin{array}{c}9.8 \\
19.51 \\
28.91 \\
38.05 \\
47.05 \\
55.81\end{array}$ & $\begin{array}{l}71 \\
67 \\
64 \\
61 \\
58 \\
54\end{array}$ & $\begin{array}{l}27.0 \\
33.8 \\
38.0 \\
42.2 \\
47.7 \\
54.2\end{array}$ \\
\hline
\end{tabular}

a Experimental Error $\approx \pm 5 \%$

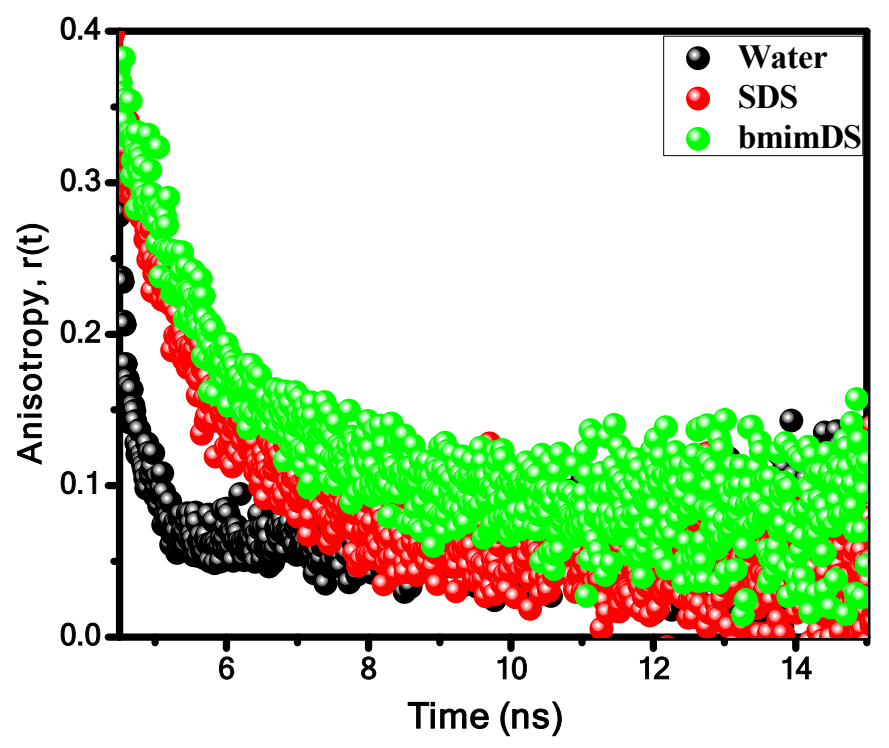


Fig. S6: Time resolved anisotropy of R6G $(20 \mu \mathrm{M})$ in water, SDS and bmimDS using the excitation laser $=440 \mathrm{~nm}$.

Table S4: Anisotropy Parameters of R6G in SDS and bmimDS

\begin{tabular}{llcclcc} 
& System & $\tau_{\mathbf{1}}(\mathbf{n s})$ & $\tau_{\mathbf{2}}(\mathbf{n s})$ & $\mathbf{B}_{\mathbf{1}}$ & $\mathbf{B}_{\mathbf{2}}$ & $\boldsymbol{\tau}_{\mathbf{a v g}}{ }^{\mathbf{a}}(\mathbf{n s})$ \\
\hline \multirow{3}{*}{ R6G } & Water & 0.269 & 0 & 1.00 & 0 & 0.26 \\
& SDS & 0.154 & 1.44 & 0.230 & 0.77 & 1.15 \\
& bmimDS & 0.989 & 3.23 & 0.617 & 0.383 & 1.85 \\
\hline
\end{tabular}

${ }^{\text {a }}$ Experimental Error $\approx \pm 5 \%$
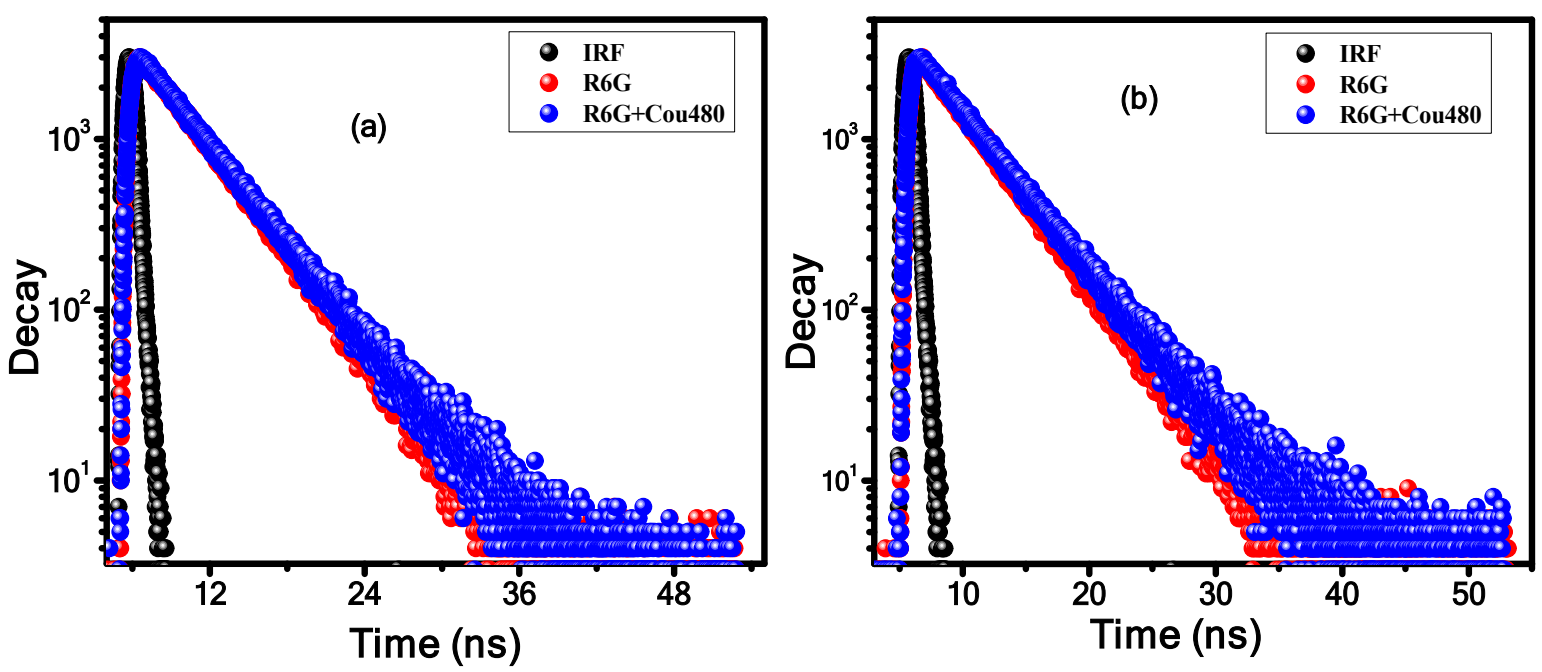

Fig. S7: Decay profile of R6G (20 $\mu \mathrm{M})$ in absence and in presence of Cou480 $(7 \mu \mathrm{M})$ in (a) SDS and $(b)$ bmimDS (excitation laser $=336 \mathrm{~nm})$. 

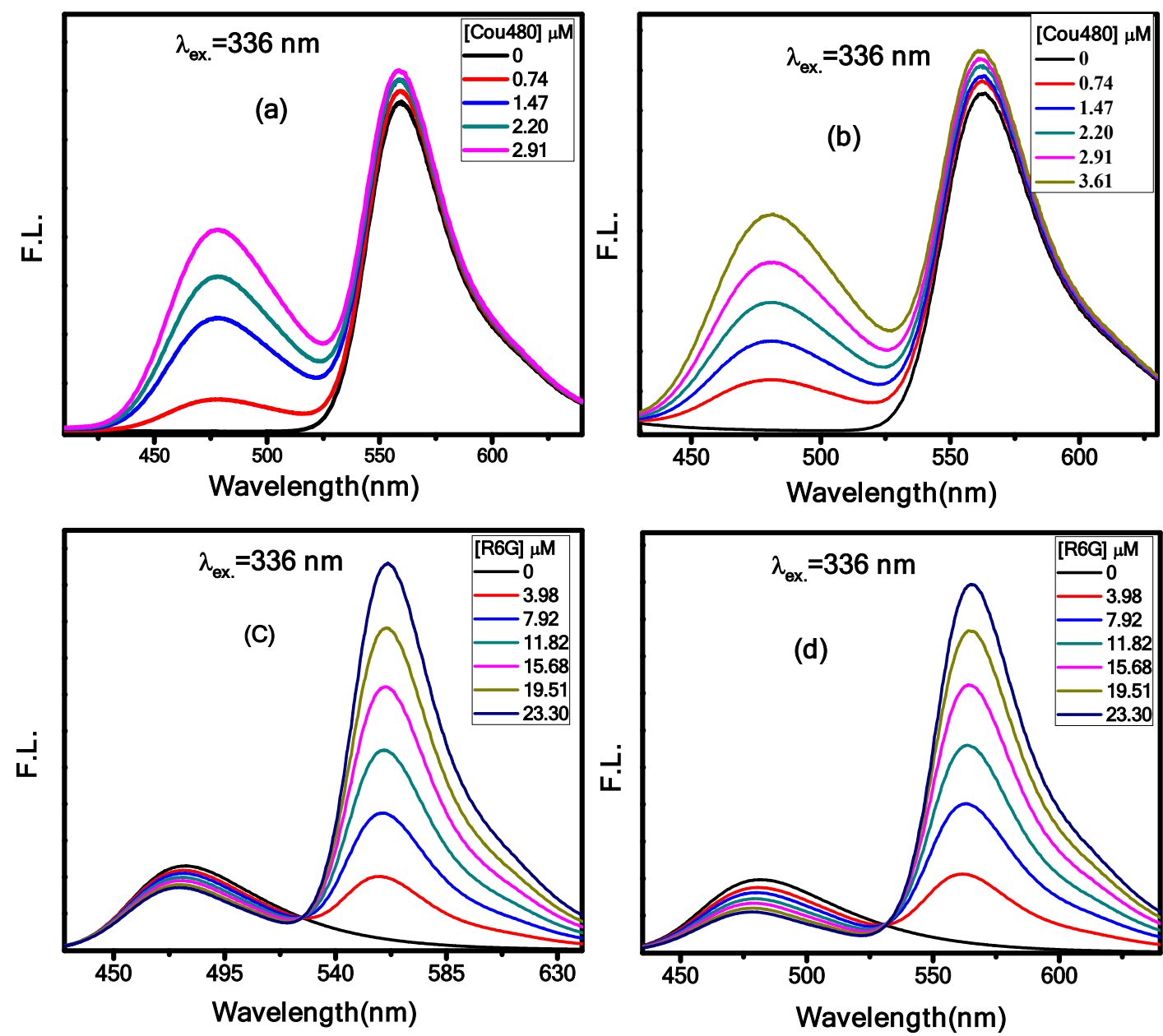

Fig. S8: Fluorescence emission spectra for the titration of R6G $(12 \mu \mathrm{M})$ with Cou480 in (a) SDS and (b) bmimDS respectively. Fluorescence emission spectra for the titration of Cou480 (5 $\mu \mathrm{M})$ with R6G in (c) SDS and (d) bmimDS respectively. 

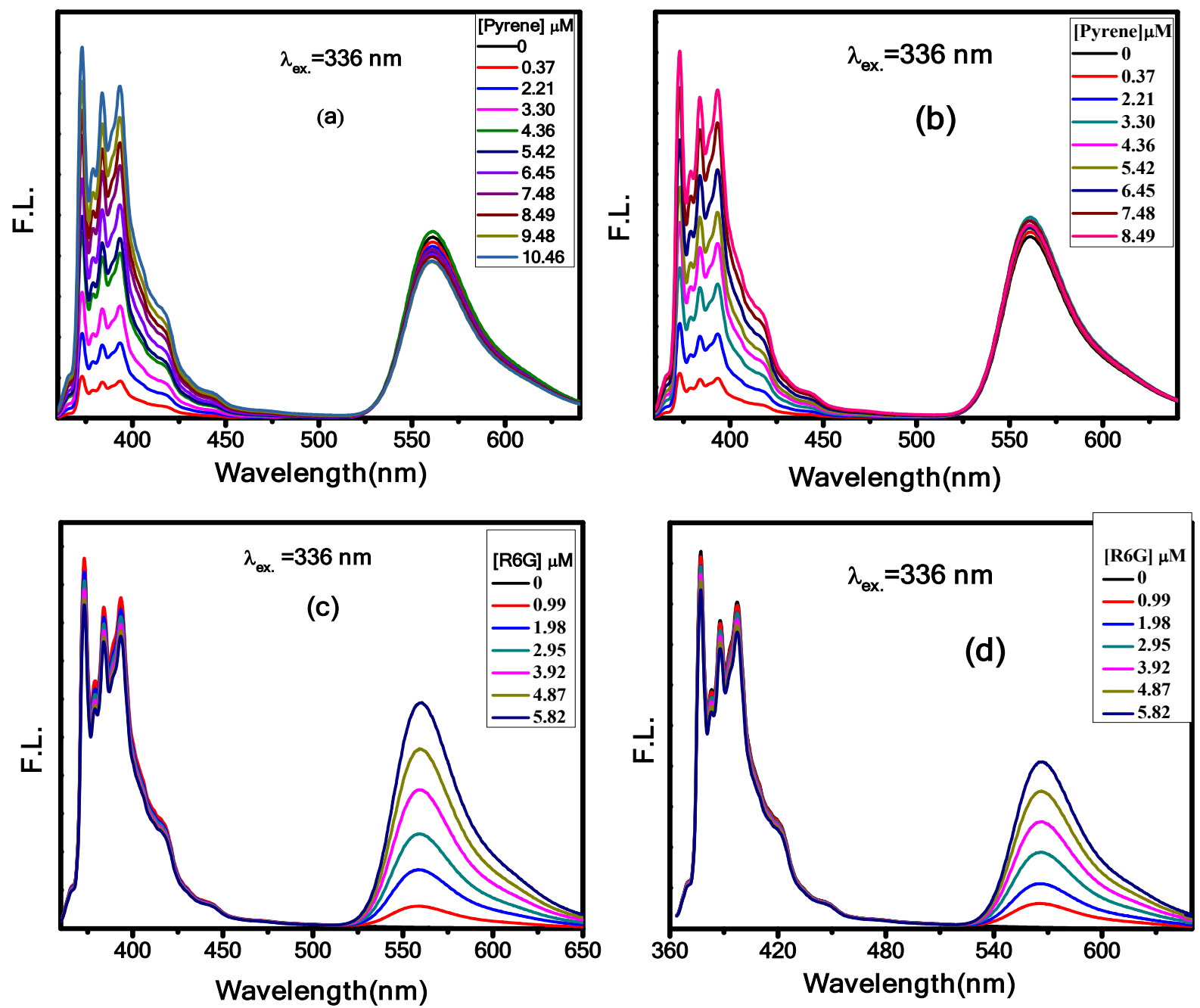

Fig. S9: Fluorescence emission spectra for the titration R6G $(12 \mu \mathrm{M})$ with the addition of Py in (a) SDS and (b) bmimDS respectively. Fluorescence emission spectra for the titration of Py (7 $\mu \mathrm{M})$ with R6G in (c) SDS and (d) bmimDS. 

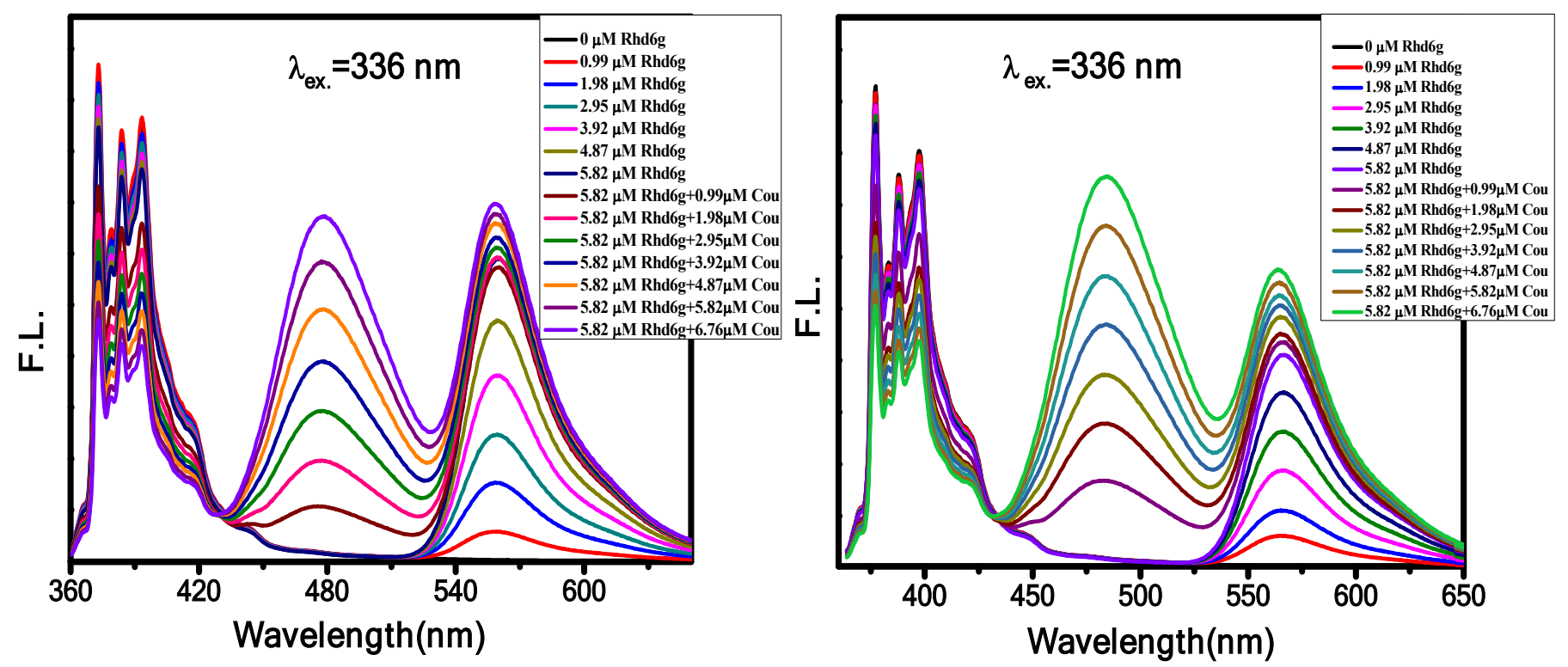

Fig. S10: Fluorescence emission spectra for the titration of Py $(7 \mu \mathrm{M})$ with the addition of R6G and Cou480 in (c) SDS and (d) bmimDS. 